\title{
The Influence of Personality and Health Beliefs on Maintaining Proper Hydration
}

\author{
Stephen M. Patterson, Deborah E. Spinks \\ Department of Psychology, Ohio University, Athens, Ohio, USA. \\ Email: patters@ohiou.edu \\ Received January $26^{\text {th }}, 2011$; revised August $14^{\text {th }}, 2011$; accepted September $26^{\text {th }}, 2011$.
}

\begin{abstract}
The present study was designed to examine factors that could facilitate or impede adherence to proper hydration. Forty volunteers (20 male, 20 female) were randomly assigned to one of two groups: Informed Group $(\mathrm{n}=20)$ and Uninformed Group $(n=20)$. Bioelectrical impedance was used to measure intracellular (ICW) and extracellular (ECW) body water at Time 1 and 2. Personality, health beliefs, and health behaviors inventories were administered at Time 1. A health information brochure on proper hydration and consequences of poor hydration was given to the Informed Group. All participants were given six 1-liter bottles of water and drank two bottles per day. Both ICW, $F(1,38)=4.79, p<.05$, and ECW, $F(1,38)=10.12, p<.005$, significantly increased for both groups, and females had significantly greater changes than males in ECW, $F(1,38)=4.43, p<.05$, and ICW, $F(1,38)=4.48, p<.05$. Health information had no significant effect on female adherence but was a significant predictor of male adherence, $\beta=.266, p<.05$. Agreeableness, $r=.36, p<.05$, and social desirability, $r$ $=.33, p<.05$, were the only personality factors related to change in ECW for the group as a whole. Health beliefs were unrelated to adherence, but general health concern, $\beta=-.053, p<.05$, was a significant predictor of change in ECW for males, although it was an inverse relationship.
\end{abstract}

Keywords: Hydration, Adherence, Health Beliefs, Health Behaviors, Personality

\section{Introduction}

Studies of adherence to positive health behaviors tend to report a broad range of adherence rates, but they all tend to demonstrate that adherence to health enhancement regimens is difficult to promote as well as assess and continues to be an issue, especially among "healthy" individuals. Fontaine and Shaw (1995) assessed attendance at an 8-week aerobics program and found that $51 \%$ of the participants could be labeled as nonadherent dropouts. Lynch et al. (1992) examined adherence to an exercise intervention for those with high cholesterol and found that only $39 \%$ of the participants attended $80 \%$ or more of the scheduled sessions. Lynch et al. (2000) measured adherence to a cholesterol-reducing diet in this same sample and found that $25 \%$ of the participants were either "vacillators" or "dropouts". In response the lack of adherence to positive health behaviors, many health professionals have begun to employ educational strategies for improving adherence (Rapoff, 1998). Previous research has found health education and psychoeducation to have significant effects on adherence to health behaviors associated with diseases such as rheumatoid arthritis, hypertension, and diabetes (Devine \& Reifschneider, 1995; Hammond, Lincoln, \& Sutcliffe, 1999; Ena et al., 2009). Unfortunately, one of the most difficult obstacles facing health promotion regimens is the impact of personality and health beliefs on adherence, especially when the benefits or consequences are not as immediately evident.

The influence of personality traits on adherence to medical and health regimens has been suggested in the health research over the last two decades (Leventhal, 1993). Previous research has indicated that several major personality dimensions (e.g., extraversion, psychoticism, and optimism) may be linked to general health behaviors, such as smoking, drinking, and nutrition. In the last decade, application of the five-factor model of personality to adherence has been advocated in order to reduce inconsistencies in this body of literature (Wiebe \& Christensen, 1996). These five broad personality dimensions, as assessed with the NEO-Five Factor Inventory (Costa \& McCrae, 1992), include: neuroticism, extraversion, openness to experience, agreeableness, and conscientiousness. Within the five-factor model of personality, the conscientiousness dimension of personality has been most consistently associated with adherence and health behaviors. In a two-part study by Booth-Kewley and Vickers (1994) examined personality and health behaviors in male U. S. Navy enlisted personnel. Results indicated that all five personality dimensions were significantly related to at least one health behavior dimension (i.e., wellness behaviors, accident control, traffic risk taking, and substance risk taking). Most results were replicated in the second study. Steptoe et al. (1994) assessed the relationship between personality variables and a healthy lifestyle in a large sample of university students and found that healthier practices were positively associated with optimism and extraversion but negatively correlated with neuroticism and psychoticism.

Another factor that is believed to play a significant role in health regimen adherence is the health belief model, which is probably the most discussed motivational construct in the health literature. The key components to the current health behavior model are: 1) perceived susceptibility, 2) perceived severity, 3) perceived benefits, 4) perceived barriers, 5) cues to action, and 6) self-efficacy. However, the self-efficacy component seems to be less incorporated into the health belief model research. Motivation for health action is hypothesized to be a product of perceived susceptibility and the severity of a health threat. Individual responses are a function of the costs and benefits of each of the actions available for dealing with the perceived threat (Leventhal, 1993). However, previous research has provided inconsistent evidence regarding the influence of the health belief model components on adherence to medical regimens among individuals with insulin-dependent diabetes 
mellitus (Bond, Aiken, \& Somerville, 1992; Ena et al., 2009) or kidney disease (Ghaddar, Shamseddeen, \& Elzein, 2009).

The role of the health belief model has rarely been examined in relation to preventive health behaviors, but studies that have assessed the influence of the health belief model in this area appear to support it. Friedman et al. (1995) found that perceived risk of skin cancer was positively related to intentions to practice skin self examination regularly, and that reasons for doing skin self examination (perceived benefits) were positively related to intention to continue skin-cancer prevention behaviors. Additionally, Sands, Archer, and Puleo (1998) found that perceived barriers significantly predicted the risk for AIDS, alcohol abuse, and poor nutrition to adherence and perceived severity of the condition. The present study assessed the influence of an adapted 4-construct health belief model on adherence to a brief hydration regimen. The 4-construct health belief model consisted of general health concern/threat, perceived susceptibility, perceived severity, and perceived benefits, and the cue to action was a brochure describing the benefits of proper hydration.

In addition to the potential impact that personality and health beliefs may have on adherence to health promotion regimens, another problem area within adherence research is the method used to assess medical regimen adherence. There are numerous methods to measure adherence, including self-reports, medication counting and weighing, and physiological measurements, but all seem to have their shortcomings. However, self-reports may still provide valuable information when used in combination with other adherence assessments, such as physiological measurements (Steele, Jackson, \& Gutmann, 1990). The present study used both self-report of fluid intake and Bioelectrical Impedance Assessment, which is a technique that measured changes in hydration status and total body water (O'Brian, Young, \& Sawka, 2002), to assess adherence to the brief hydration regimen.

Therefore, the goals of the present study were to: 1) examine whether health promotion information increased adherence to a three-day hydration regimen, 2) assess the influence of personality characteristics and health behaviors hydration adherence, and 3) determine the effects of the health belief model (i.e., general health concern/threat, perceived susceptibility, perceived severity, perceived benefits, and cue to action) on adherence to hydration enhancement.

\section{Methods}

\section{Participants}

Complete data was obtained from 40 participants $(20$ males and 20 females) selected from an undergraduate mass screening. All participants were between 18 and 20 years of age $(M=$ 18.76) and were currently enrolled in an undergraduate psychology class. Requirements for participation in the study were initially acquired with a mass-screening questionnaire. Potential participants were telephoned and briefly interviewed with a health information questionnaire to confirm their health status. Requirements for participation included 1) being between 18 and 30 years of age, 2) being in good physical health as indicated by the absence of a chronic or acute illness, 3) body weight no greater than $20 \%$ above ideal weight as defined by the Metropolitan Life Insurance Standards, and 4) report drinking less than $1500 \mathrm{ml}$ of water a day.

\section{Questionnaires}

Health Beliefs Questionnaire: The health belief questionnaire is a 26-item psychosocial measure designed to assess an individual's perceptions about his or her health behavior. This questionnaire was adapted from the Health Belief Model Questionnaire (Weissfeld, Kirscht, \& Brock, 1990), a 32-item measure that addresses 6 health belief components: general health threat, health concern, susceptibility, severity, and medical and self- help benefits. The items specific to individuals with high blood pressure were removed, resulting in 4 compressed categories (health threat/concern, perceived susceptibility, perceived severity, and perceived benefits). Coefficient alpha reliabilities for the original questionnaire range from .65 to .89 , and confirmatory factor analysis identified the original six factors (Weissfeld et al., 1990). Coefficient alpha reliabilities for the adapted 4-construct questionnaire ranged from .61 to .81 .

NEO Five-Factor Inventory (NEO-FFI): The NEO-FFI (9) (Costa, \& McCrae, 1992) consists of 60 items that assess five broad domains of personality: neuroticism, extraversion, openness to experience, agreeableness, and conscientiousness. Correlations with the full 180 -item revised NEO Personality Inventory domains have ranged from .75 to .94 across normative samples. Coefficient alphas have ranged from .68 to .90, and convergent and discriminant validity is seen in the cross-observer correlations with the NEO PI-R scales (Costa, \& McCrae, 1992).

Marlowe-Crowne Social Desirability Scale. The MarloweCrowne Social Desirability Scale (19) (Crowne \& Marlowe, 1960 ) is one of the most widely used measures of need for approval and is comprised of 33 true-false items. Eighteen items assess the tendency to attribute positive qualities toward oneself, and the remaining 15 items assess the tendency to deny negative qualities in oneself. Construct validity has been established and coefficient alpha reliabilities have ranged from .73 to .88 in normative samples (Paulhus, 1991).

Food and Drink Inventory. This inventory was completed at the beginning of Session 1 and Session 2. Participants were instructed to write down everything consumed (i.e., food and drinks) within the last 24 hours, being as specific as possible. Due to the diuretic effects of alcohol, participants who reported consuming more than $1100 \mathrm{ml}$ of alcohol (approximately 3 beers) in the previous 24 hours were not included in the analysis.

Health Behavior Questionnaire. This 6-item questionnaire assessed 6 health behaviors: smoking, drinking, exercising, unhealthy snacking, fruit consumption, and sleep habits.

Adherence Questionnaire. This brief self-report questionnaire contained 4 questions regarding how much of the 6 liters was drank over the 3-day regimen; if they drank the instructed 2 liters per day; when they drank the water; and if they intended to continue drinking more water than they used to after participating the study.

\section{Physiological Measures}

Bioelectrical Impedance Assessment (BIA): Multifrequency BIA (BODYSTAT LTD $®$ Multiscan 5000 model: Douglas, Isle of Man, UK) measures the distribution of extracellular body water (ECW) and intracellular body water (ICW). BIA utilizes the resistance and conductance of a weak electrical current that is passed through the body between electrodes placed on the right hand and the right foot. Since variation in body fluids during the menstrual cycle affects BIA, females were not scheduled for assessments during menses. Studies using BIA with healthy subjects have indicated that this is a valid (Berger, Rousset, MacCormack, \& Ritz, 2000; Segal et al., 
1991) and reliable $(19,21)$ (Berger et al., 2000; Shanholtzer, \& Patterson, 2002) measure of total body water.

\section{Health Promotion Information}

During the first session, half of the participants received a health promotion brochure briefly explaining the benefits of proper hydration and the consequences of dehydration.

\section{Hydration Fluid}

Six 1-liter bottles of commercially available bottled water were provided to each participant, and each bottle was labeled with the day it was to be consumed.

\section{Procedure}

Initial qualification was assessed at a mass screening of introductory psychology students. Students who estimated drinking less than 1000 milliliters of water each day were contacted by telephone in order to re-verify their daily liquid consumption and asked some additional health information. Session 1 and Session 2 appointments were then scheduled with the participant. All eligible participants were randomly assigned to one of two groups: the Informed Group or the Uninformed Group. Lastly, all participants were instructed to refrain from eating or drinking in the hour prior to their appointment to control for short-term dietary effects on body water.

Upon arrival to the psychophysiology laboratory, informed consent was reviewed and obtained, and each participant was randomly assigned to either the Hydration Benefits Informed Group or the Uninformed Group. After being consented and assigned to one of the two groups, the Food and Drink Inventory, the Health Behavior Questionnaire, the Health Beliefs Questionnaire, the NEO Five-Factor Inventory, and the Marlowe-Crowne Social Desirability Scale were administered. Next, height and weight were recorded for the BIA recording, and participants were subsequently instructed to lie still on a massage table for a 15-minute rest period prior to the BIA recording. The BIA recording took approximately 5 minutes to complete.

Following the BIA recording, the participants assigned to the Informed Group read through a health benefits brochure which described the psychological and physical health benefits of keeping well hydrated. Any questions the participants had about the information in the brochure were answered. Participants in the Uninformed Group were not given this brochure, and discussion was minimal. Subsequently, six 1-liter bottles of water were provided to all participants with instructions to drink 2 per day (the recommended daily amount) for the next 3 days as labeled on the bottles. Participants were also told they would complete a final questionnaire and receive their BIA feedback at the final session. In order to avoid influencing adherence to the regimen, participants were not told that they would undergo a second BIA recording.

The second session was scheduled for the fourth day at the same time as the first session. At this session, each participant completed a brief questionnaire on their adherence to the regimen and then had a second BIA recording to measure changes in their body water. Lastly, the investigator reviewed the body water readings with all participants and provided the health benefits brochure to the participants in the Uninformed Group. All participants were then debriefed and offered the chance to ask any questions.

\section{Data Reduction}

Body water change scores suggested level of adherence to the hydration regimen. A composite self-reported adherence score was calculated using the first two questions on the adherence questionnaire (i.e., how much of the 6 liters of water they drank and if they drank the instructed amount per day) into a self-report adherence scale. Adherers complied fully with the regimen, whereas non-adherers were noncompliant with at least one aspect of the regimen.

\section{Data Analysis}

Pearson product moment correlations were conducted to evaluate the relationships among the variables. One-way ANOVAs were performed to examine differences between groups. Separate 2-between $\times 2$-within repeated measures ANOVAs were conducted to assess the effects of time, condition, and sex on the two measures of change in body water, and a 2 -between $\times 2$-between $\times 2$-within repeated measures MANOVA was conducted to assess Sex by Condition effects. Additionally, due to the sex differences found on the body water measures, several MANCOVAs were performed, with sex entered as a covariate. Similarly, separate stepwise multiple regression analyses were performed for males and females, as well as the sample as a whole. Sex (for the whole-group analysis only) and BMI were forced into Step 1 due to their association with body water measurements; the corresponding baseline body water measure and condition were entered in Step 2; the current health behaviors and health beliefs were entered in Step 3 ; and the personality measures were entered in Step 4.

\section{Results}

\section{Descriptive Characteristics}

An ANOVA indicated that the Informed Group and the Uninformed Group did not differ on any demographic variables or baseline body water measure. However, results revealed that females had significantly lower baseline body water measurements than males: ECW, $F(1,38)=82.58, p<.0001$, and $\mathrm{ICW}$, $F(1,38)=178.37, p<.0001$. Furthermore, females had significantly greater increases on both measures of body water: $\mathrm{ECW}, F(1,38)=4.43, p<.05$, and ICW, $F(1,38)=4.48, p$ $<.05$, suggesting better adherence (see Table 1$)$.

\section{Adherence to the Hydration Regimen}

Correlations revealed that BMI was significantly positively correlated with baseline measures of ICW, $r=.59, p<.001$, and ECW, $r=.61, p<.001$, but inversely correlated with change in ECW, $r=-.33, p<.05$, indicating that those with a larger BMI had higher baseline measures of body water and experienced smaller changes in body water by Session 2. Of the participants' self-reported estimates of liquids consumed daily, caffeinated coffee and tea were significantly inversely correlated with change in ECW, $r=-.34, p<.05$; and water was significantly inversely correlated with change in ICW, $r=-.37, p<.05$.

Repeated measures ANOVAs revealed a significant main effect of Time for ICW, $F(1,38)=4.79, p<.05$, and ECW, $F(1$, $38)=10.12, p<.005$, indicating that both body water measures were greater at Session 2. Change in ECW, however, was greater than change in ICW, but this difference was not significant. Additionally, a significant Time by Sex interaction was found for ICW, $F(1,38)=4.79, p<.05$, indicating that ICW increased from Session 1 to Session 2 for the females but not the males.

Repeated measures ANOVAs revealed that Condition (Informed vs. Uninformed) had no significant effect on the body 
water measurements at Session 1 and Session 2. However, further analyses did reveal a significant Sex by Condition interaction for change in ICW, $F(1,38)=5.38, p<.05$ (see Figure 1). This interaction reflects a decrease in ICW for males in the Uninformed condition and an increase for males in the Informed condition, whereas females in the Uninformed condition had greater increases in ICW than females in the Informed condition. Stepwise multiple regression analyses were conducted by sex in order to further examine this interaction (see Table 2). For males, condition, $\beta=.266, p<.05$, was the only significant predictor of change in ICW, but it accounted for $26.0 \%$ of the variance with BMI also in the model.

Table 3 displays the final significant regression equation for the sample as a whole. Sex, $\beta=.174, p=.069$, and BMI, $\beta=$ $-.023, p=.054$, were marginally significant predictors of change in ECW, whereas low general health concern, $\beta=-.042$, $p<.05$, and high social desirability, $\beta=.018, p<.05$, were significant predictors of increased ECW hydration. Together, all four variables accounted for $37.5 \%$ of the variance in change in ECW. Conversely, none of the variables significantly predicted change in ICW.

Correlations and an ANOVA revealed that there was no significant relationship between self-reported non-adherers $(n=6)$ and adherers $(n=34)$ on change in ECW or ICW. Paired-samples $t$-tests revealed that both groups had significant increases in ECW, $t(5)=-3.08, p<.05$ and $t(33)=-2.54, p<.05$, respectively, although the adherers also had a marginally significant increase in ICW, $t(33)=-1.82, p=.08$.

\section{Health Behaviors, Health Beliefs, and Adherence}

Correlations were calculated to assess the relationship between general health behaviors and health beliefs and changes in body water. Current health behaviors were not significantly related to change in ECW or change in ICW. Of the health beliefs, only general health concern was significantly inversely related to change in ECW, $r=-.33, p<.05$, indicating that those with greater health concern actually had smaller changes in ECW. However, ANOVAs revealed that no health behavior or health belief had a significant effect on change in body water.

The final significant regression equations for the sample as a

Table 1.

Means and standard deviations for body mass and body water measures by sex and condition.

\begin{tabular}{cccccc}
\hline \multicolumn{5}{c}{ Males $(n=10)$} & \multicolumn{3}{c}{ Females $(n=10)$} & $p$ \\
\hline Uninformed Group $(n=20)$ & & & & & \\
Body Mass Index (BMI) & 24.55 & $(2.97)$ & 21.94 & $(1.67)$ & .026 \\
Session 1 & & & & & \\
ECW & 18.98 & $(1.81)$ & 14.41 & $(1.01)$ & .000 \\
ICW & 22.45 & $(2.49)$ & 13.63 & $(1.24)$ & .000 \\
Session 2 & & & & & \\
ECW & 19.00 & $(1.89)$ & 14.59 & $(.97)$ & .000 \\
ICW & 22.32 & $(2.56)$ & 13.92 & $(1.15)$ & .000 \\
Change in & & & & & \\
ECW & .02 & $(.26)$ & .26 & $(.33)$ & ns \\
ICW & -.13 & $(.13)$ & .30 & $(.48)$ & .014 \\
Informed Group ( $n=20)$ & & & & & \\
Body Mass Index (BMI) & 24.05 & $(2.64)$ & 23.36 & $(3.16)$ & ns \\
Session 1 & & & & & \\
ECW & 19.19 & $(1.99)$ & 14.89 & $(1.29)$ & .000 \\
ICW & 22.79 & $(2.58)$ & 14.39 & $(1.67)$ & .000 \\
Session 2 & & & & & \\
ECW & 19.34 & $(1.89)$ & 15.17 & $(1.10)$ & .000 \\
ICW & 22.92 & $(2.67)$ & 14.52 & $(1.62)$ & .000 \\
Change in & & & & & \\
ECW & .15 & $(.31)$ & .31 & $(.31)$ & ns \\
ICW & .13 & $(.31)$ & .12 & $(.12)$ & $\mathrm{ns}$ \\
\hline
\end{tabular}

Note: $\mathrm{ICW}=$ intracellular water; $\mathrm{ECW}=$ extracellular water; $\mathrm{ns}=$ not significant.

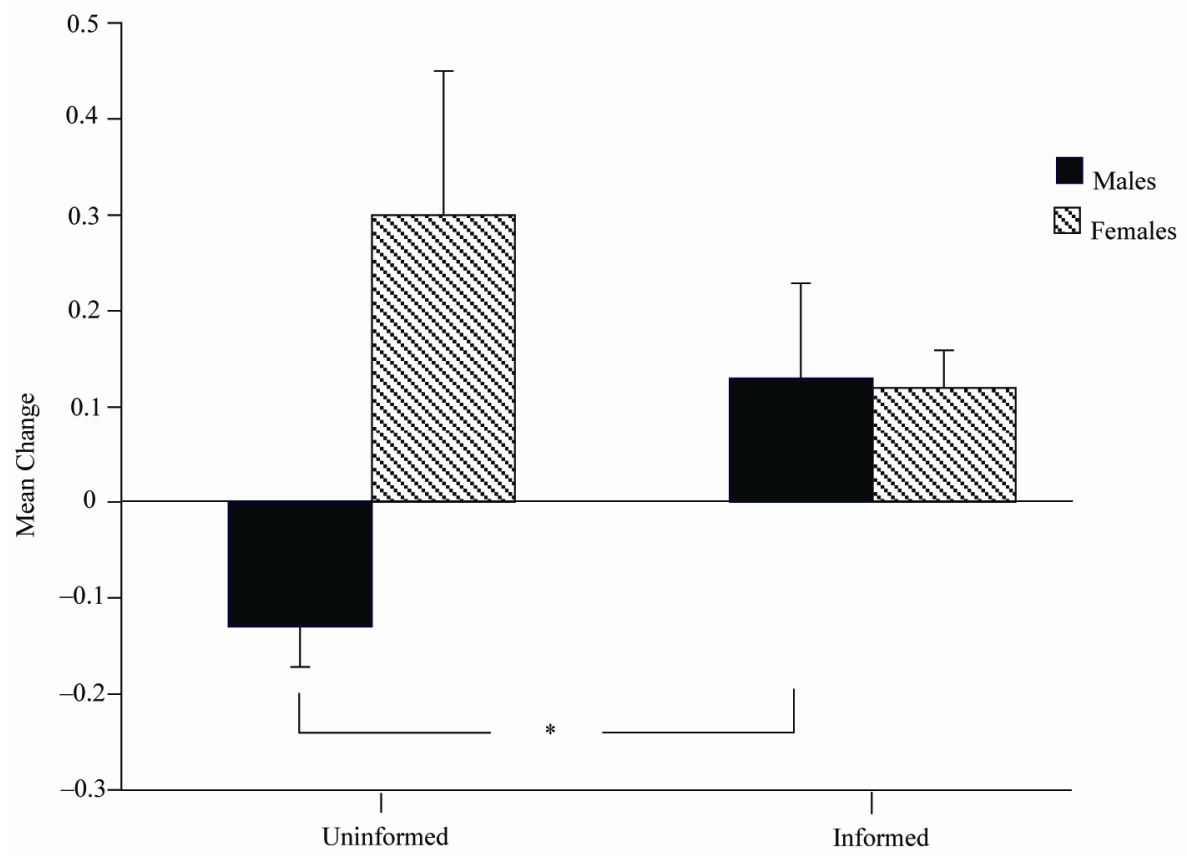

Figure 1.

Sex by condition interaction for change in intracellular body water $\left({ }^{*} p<.05\right)$. 
Table 2.

Predictive value of baseline physiological measures, condition, health behaviors/beliefs, and personality characteristics on changes in body water by sex.

\begin{tabular}{ccccc}
\hline Variable & $\beta$ & Beta & $t$-value & $p$ \\
\hline Females $(n=20)$ & & \\
BMI & -.052 & -.380 & -1.86 & $\mathrm{~ns}$ \\
Neuroticism & -.026 & -.499 & -2.45 & .025 \\
& Males $(n=20)$ & & \\
$\Delta \mathrm{ICW}$ & & & & \\
BMI & .012 & .124 & .59 & $\mathrm{~ns}$ \\
Condition & .266 & .506 & 2.42 & .027 \\
$\Delta \mathrm{ECW}$ & & & & \\
BMI & -.016 & -.149 & -.72 & $\mathrm{~ns}$ \\
Health concern & -.053 & -.513 & -2.49 & .023 \\
\hline
\end{tabular}

Note: ICW = intracellular water; ECW = extracellular water; Note: ICW = intracellular water; $\mathrm{ECW}=$ extracellular water;

Table 3.

Predictive value of sex, baseline physiological measures, condition, health behaviors/beliefs, and personality characteristics on changes in body water $(n=40)$.

\begin{tabular}{ccccc}
\hline Variable & $\beta$ & Beta & $t$-value & $p$ \\
$\Delta$ ECW & & & & \\
Sex & .174 & .282 & 1.87 & $\mathrm{~ns}$ \\
BMI & -.023 & -.204 & 1.99 & $\mathrm{~ns}$ \\
Health concern & -.042 & -.324 & -2.39 & .022 \\
Social desirability & .018 & .329 & 2.46 & .019 \\
\hline
\end{tabular}

Note: $\mathrm{ECW}=$ extracellular water; $\mathrm{ns}=$ not significant.

whole revealed that current health behaviors and health beliefs were not significant predictors of change in ICW (see Table 3). However, low general health concern, $\beta=-.042, p<.05$, was again found to be a significant predictor of greater change in ECW. Furthermore, additional stepwise multiple regression analyses conducted by Sex revealed that low general health concern, $\beta=-.053, p<.05$, was a significant predictor of greater change in ECW for males only, accounting for $32.1 \%$ of the variance with BMI also in the model (see Table 2)

\section{Personality and Adherence}

Change in ECW was significantly positively related to agreeableness, $r=.36, p<.05$, and social desirability, $r=.33, p$ $<.05$, but no other personality measures were significantly related to changes in body water. However, ANOVAs revealed that only openness had a significant effect on change in ICW, $F(1,39)=2.42, p<.05$, after controlling for sex, with those scoring higher on openness showing smaller changes in ICW. No other individual personality effects were found.

The regression analyses revealed that none of the personality characteristics were significant predictors of change in ICW in the sample as a whole (see Table 3 ). Furthermore, social desirability, $\beta=.018, p<.05$, was the only personality variable that was a significant predictor of change in ECW. Further regression analysis by sex revealed that none of the personality variables were significant predictors of change in ICW or ECW for males, nor were they significant predictors of change in ECW for females (see Table 2). Only neuroticism, $\beta=-.026, p<.05$, was a significant predictor of change in ICW for females, although BMI, $\beta=-.052, p=.08$, was marginally significant.
Together, BMI and neuroticism accounted for $32.0 \%$ of the variance in change in ICW for females.

\section{Discussion}

This study was designed to examine the individual predictors of adherence to a brief hydration regimen. The predictors examined in the present study included health education, health behaviors and beliefs, and personality characteristics. First, results indicated that individuals who drank more coffee and tea had smaller increases in ECW, which may suggest possible diuretic effects of caffeine on decreasing one's hydration status. Additionally, participants who reported generally drinking more water (e.g., between 1000 and $1500 \mathrm{ml}$ per day) may have had higher ICW at Session 1 or inadvertently attenuated their usual daily fluid consumption when given the additional 6 liters and therefore the changes in hydration status for these participants may not have been as great as it would have had they truly supplemented their diet with the additional regimen fluid.

In terms of the effects of education on hydration adherence (Devine, \& Reifschneider, 1995; Hammond et al., 1999), the results of the present study do indicate that participants demonstrated a small, yet significant increase in both ICW and ECW from Session 1 to Session 2. However, a Sex by Time interaction revealed that only females significantly increased overall. Further analyses revealed a noteworthy Sex by Condition interaction that indicated a decrease in ICW for males in the uninformed group, but a significant increase in ICW for males in the informed group. Conversely, the females in the both groups had an increase in ICW, although, a greater increase was found in the uninformed group. Thus, the main goal of the present study was only partially supported, since the effect of the health information (cue to action) was only significant for the males. This finding is of particular interest, since intracellular body water is less sensitive to acute body water changes, in comparison to extracellular body water.

The small increases in body water, the gender differences in changes in body water, and the effect of the health information are of particular interest in this study, and a number of reasons may help explain some of these findings. First, the sample consisted of primarily healthy college freshmen, a very restricted group. Young people of this age have been found to be less likely to practice health-promoting behaviors than older adults (Walker, Volkan, Sechrist, \& Pender, 1988). Secondly, college students are also known to be a more unrealistically optimistic population, which has been related to poorer health behaviors, such as decreased exercise and poorer health prevention knowledge (e.g., Davidson, \& Prkachin, 1997). Lastly, the gender effects of patient health information on adherence to the hydration regimen may warrant further investigation, since such effects have not been reported in previous health literature of this kind.

Self-reports of adherence were not associated with any of the changes in body water. The self-reported adherers and nonadherers both significantly increased their ECW, but only the full adherers demonstrated a marginally significant increase in ICW as well, which suggests better adherence. The lack of a relationship between self-reported adherence and physiological measures was expected, since it has been a frequent finding in the health literature (Rand, \& Weeks, 1998).

\section{Personality, Health Behaviors, and Adherence}

The present study examined the relationship between personality characteristics and adherence. Since previous literature 
has found conscientiousness (Christensen, \& Smith, 1995; Lemos-Giraldez, \& Fidalgo-Aliste, 1997) to be a common predictor of adherence and preventive health behaviors, the fourth hypothesis predicted that conscientiousness would also be strongly related to better adherence to the hydration regimen. However, conscientiousness was not related to any body water changes, and only agreeableness was related to greater changes in ECW. However, agreeableness was positively related to better adherence, which corresponds to previous studies (e.g., Lemos-Giraldez \& Fidalgo-Aliste, 1997).

In previous literature, the other four dimensions of personality have been variably related to a number of health behaviors. In the present study, neuroticism was found to be a significant predictor of change in ICW for females only. Individuals who score high in neuroticism are generally more susceptible to psychological distress, which can interfere with impulse control and adaptive coping. Thus, the females in the present study may have had more negative feelings about some aspect of the study, which their adherence. These results partially correspond to previous studies that found neuroticism to be associated with fewer wellness behaviors (Booth-Kewley, \& Vickers, 1994). Social desirability, on the other hand, was the only personality variable found to significantly predict change in ECW for the sample as a whole. Since increases in ECW register before changes in ICW, it can be suggested that participants scoring high in social desirability may have consumed the water closer to their second session in order to comply with the researcher's instructions and, thus, present themselves in a favorable light. Though the literature on social desirability and adherence is scarce, the findings were in the expected direction.

In terms of examining the effects of current health behaviors on health regimen adherence, general health behaviors, as assessed in the present study, were not found to be correlated with any of the BIA body water measures. This finding was in contrast to that of Friedman et al. (1995) who examined skin-cancer screening behaviors, but since more comprehensive studies in this area are lacking, conclusions are provisional.

\section{Health Beliefs, and Adherence}

The third goal of the study was to assess whether positive health beliefs would be related to better adherence. First, the health information (cue to action), analyzed separately as Condition, was a significant predictor of only the change in ICW for the males. Analyses of the adapted 4-construct model indicated that health concern (which includes perceived threat) was significantly inversely related to and a significant predictor of change in ECW, which suggests that those with greater health concerns were less likely to adhere to this regimen. Thus, the third hypothesis is not supported. These findings are comparable to those of Bond et al. (1992), but Wiebe and Christensen (1997) found that high scores in health beliefs (severity, susceptibility, and benefits) were associated with better adherence. Such inconsistencies suggest that further studies in this area are necessary.

\section{Limitations of the Present Study}

Several limitations of the present study should be noted. First, participants were all young, healthy college students, so the findings may not generalize to older individuals or less healthy populations. Second, the sex of the experimenter may have had some influence on adherence, as suggested by the sex differences in body water changes. Counterbalancing the sex of the experimenter and participants may help minimize experimenter influence. Third, the participants received class credit for par- ticipating, which may have positively influenced adherence.

Fourth, the BIA measurements alone may not have been the most accurate way to estimate adherence to the hydration regimen. Additional factors, such as solid foods eaten and liquid voided were not taken into consideration in the analyses. Such individual differences may have affected the body water measurements.

The Health Behaviors Questionnaire used in the present study was adapted from Lemos-Giraldez and Fidalgo-Aliste (1997) and may not have been sufficiently comprehensive, as noted by the original authors. Furthermore, the Health Beliefs Questionnaire that was adapted from Weissfeld et al. (1990) may not have been adequate, since most previous measures have been illness-specific (e.g., Weissfeld et al., 1990; Given, Given, Gallin, \& Condon, 1983). Consequently, the need for a more reliable and valid measure of these constructs remains.

\section{Conclusion and Directions for Future Research}

In summary, the results of the present study suggest that young adults were not substantially influenced by the health promotion information they received. In addition, some health beliefs and personality components were significant predictors of adherence to the brief hydration regimen, though some of these findings were not consistent with previous literature. These incongruities may be due to the inadequacies of existing measures or to the specific hydration focus of the present study. Because of the novelty of this study, further studies are being conducted to better understand the pattern and scale of the BIA changes associated with changes in hydration status. Future studies utilizing hydration enhancement regimens should also assess or control for solid food contributions to body water and amount of liquid voided. Nonetheless, it is still readily apparent from the present study, as well as previous studies, that the numerous and complex predictors of adherence makes the search for the most effective health promotion approach all the more complicated.

\section{References}

Becker, M. H., Drachman, R. H., \& Kirscht, J. P. (1974). A field experiment to evaluate various outcomes of continuity of physician care. American Journal of Public Health, 64, 1062-1070. doi:10.2105/AJPH.64.11.1062

Berger, V. A., Rousset, P., MacCormack, C., \& Ritz, P. (2000). Reproducibility of body composition and body water spaces measurements in healthy elderly individuals. Journal of Nutrition, Health \& Aging, 4, 243-245.

Bond, G. G., Aiken, L. S., \& Somerville, S. C. (1992). The health belief model and adolescents with insulin-dependent diabetes mellitus. Health Psychology, 11, 190-198. doi:10.1037/0278-6133.11.3.190

Booth-Kewley, S., \& Vickers, R. R. (1994). Associations between major domains of personality and health behavior. Journal of Personality, 62, 281-298. doi:10.1111/j.1467-6494.1994.tb00298.x

Christensen, A. J., \& Smith, T. W. (1995). Personality and patient adherence: Correlates of the five-factor model in renal dialysis. Journal of Behavioral Medicine, 18, 305-313. doi:10.1007/BF01857875

Costa, P. T., \& McCrae, R. R. (1992). Revised NEO Personality Inventory and NEO Five-Factor Inventory: Professional Manual. Odessa, FL: Psychological Assessment Resources.

Crowne, D. P., \& Marlowe, D. (1960). A new scale of social desirability independent of psychopathology. Journal of Consulting Psychology, 24, 349-354. doi:10.1037/h0047358

Davidson, K., \& Prkachin, K. (1997). Optimism and unrealistic optimism have an interacting impact on health-promoting behavior and knowledge changes. Personality \& Social Psychology Bulletin, 23, 617-625. doi:10.1177/0146167297236005

Devine, E. C., \& Reifschneider, E. (1995). A meta-analysis of the ef- 
fects of psychoeducational care in adults with hypertension. Nursing Research, 44, 237-245. doi:10.1097/00006199-199507000-00009

Ena, J., Casan, R., Lozano, T. Leach, A., Algado, J. T., \& Navarro_Diaz, F. J., (2009). Long-term improvements in insulin prescribing habits and glycaemic control in medical inpatients associated with the introduction of a standardized educational approach. Diabetes Research and Clinical Practice, 85, 159-165. doi:10.1016/j.diabres.2009.05.011

Fontaine, K. R., \& Shaw, D. F. (1995). Effects of self-efficacy and dispositional optimism on adherence to step aerobic exercise classes. Perceptual \& Motor Skills, 81, 251-255. doi:10.2466/pms.1995.81.1.251

Friedman, L. C., Weinberg, A. D., Webb, J. A., Cooper, H. P., \& Bruce, S., (1995). Skin cancer prevention and early detection intentions and behavior. American Journal of Preventive Medicine, 11, 59-65.

Ghaddar, S., Shamseddeen, W., \& Elzein, H., (2009). Behavioral modeling to guide adherence to fluid control in hemodialysis patients. Journal of Renal Nutrition, 19, 153-160. doi:10.1053/j.jm.2008.08.011

Given, C. W., Given, B. A., Gallin, R. S., \& Condon, J. W. (1983). Development of scales to measure beliefs of diabetic patients. Research in Nursing and Health, 6, 127-141. doi:10.1002/nur.4770060306

Hammond, A., Lincoln, N., \& Sutcliffe, L. (1999). A crossover trial evaluating an educational-behavioural joint protection programme for people with rheumatoid arthritis. Patient Education \& Counseling, 37, 19-32. doi:10.1016/S0738-3991(98)00093-7

Lemos-Giraldez, S., \& Fidalgo-Aliste, A. M. (1997). Personality dispositions and health-related habits and attitudes: A cross-sectional study. European Journal of Personality, 11, 197-209. doi:10.1002/(SICI)1099-0984(199709)11:3<197::AID-PER283>3.0. $\mathrm{CO} ; 2-\mathrm{H}$

Leventhal, H. (1993). Theories of compliance, and turning necessities into preferences: Application to adolescent health action. In N. A. Krasnegor, L. Epstein, S. B. Johnson, \& S. J. Yaffe (Eds.), Developmental aspects of health compliance behavior (pp. 91-124). Hillsdale, NJ: Lawrence Erlbaum Associates.

Lynch, D., Birk, T., Weaver, M., Gohara, A., Leighton, R., Repka, F., \& Walsh, M. (1992). Adherence to exercise interventions in the treatment of hypercholesterolemia. Journal of Behavioral Medicine, 15, 365-377. doi:10.1007/BF00844729

Lynch, D., Repka, F., Nagel, R., Birk, T., Gohara, A., Leighton, R., Walsh, M., \& Weaver, M., (2000). Prediction of dietary adherence in cholesterol reduction: Relative contribution of personality variables and health attitudes. Psychology and Health, 15, 821-828. doi: $10.1080 / 08870440008405584$

Mulkana, S. S., \& Hailey, B. J. (2001). The role of optimism in health- enhancing behavior. American Journal of Health Behavior, 25, 388395.

O’Brian, C., Young, A. J., Sawka M. N. (2001). Bioelectrical impedance to estimate changes in hydration status. International Journal of Sports Medicine, 23, 361-366. doi:10.1055/s-2002-33145

Paulhus, D. L. (1991). Measurement and control of response bias. In J. P. Robinson, P. R. Shaver, \& L. S. Wrightsman (Eds.), Measures of personality and social psychological attitudes (pp. 17-59). San Diego, CA: Academic Press

Rand, C. S., \& Weeks, K. (1998). Measuring adherence with medication regimens in clinical care and research. In S. A. Shumaker, E. B. Schron, J. K. Ockene, \& W. L. McBee (Eds.), The handbook of health behavior change (Second edition) (pp. 114-135). New York: Springer Publishing Co.

Rapoff, M. A. (1998). Adherence issues among adolescents with chronic disease. In S. A. Shumaker, E. B. Schron, J. K. Ockene, \& W. L. McBee (Eds.), The handbook of health behavior change (Second ed.) (pp. 377-408). New York: Springer Publishing Co.

Sands, T., Archer, J., \& Puleo, S. (1998). Prevention of health-risk behaviors in college students: Evaluating seven variables. Journal of College Student Development, 39, 331-342.

Segal, K. R., Burastero, S., Chun, A., Coronel, P., Pierson, R. N. Jr., Wang, J. (1991). Estimation of extracellular and total body water by multiple-frequency bioelectrical-impedance measurement. American Journal of Clinical Nutrition, 54, 26-29.

Shanholtzer. B. A., \& Patterson, S. M. (2002). Fluid hydration status assessment in behavioral medicine research: Seven-day test-retest reliability. Annals of Behavioral Medicine, 24, 120.

Steele, D. J., Jackson, T. C., \& Gutmann, M. C. (1990). Have you been taking your pill? The adherence-monitoring sequence in the medical interview. The Journal of Family Practice, 30, 294-299.

Steptoe, A., Wardle, J., Vinck, J., Tuomisto, M., Holte, A., \& Wichstrom, L. (1994). Personality and attitudinal correlates of healthy and unhealthy lifestyles in young adults. Psychology and Health, 9, 331343. doi: $10.1080 / 08870449408407492$

Walker, S. N., Volkan, K., Sechrist, K. R., \& Pender, N. J. (1988). Health-promoting lifestyles of older adults: Comparisons with young and middle-aged adults, correlated, and patterns. Advances in Nursing Science, 11, 76-90.

Weissfeld, J. L., Kirscht, J. P., \& Brock, B. M. (1990). Health beliefs in a population: The Michigan Blood Pressure Survey. Health Education Quarterly, 17, 141-155. doi:10.1177/109019819001700202

Wiebe, J. S., \& Christensen, A. J. (1996). Patient adherence in chronic illness: Personality and coping in context. Journal of Personality, 64, 815-835. doi:10.1111/j.1467-6494.1996.tb00945.x 